\title{
Seismic Surface Wave Testing for Investigating the Shallow Soil Profile
}

\author{
Siti Zuraidah $\mathrm{Z}^{1 \mathrm{a}^{*}}$,Aziman $\mathrm{M}^{2, \mathrm{~b}}$,Ariffuddin $\mathrm{J}^{1, \mathrm{c}}$ and Mohammad Faiz L.A. ${ }^{1, \mathrm{~d}}$ \\ ${ }^{1}$ Faculty of Electrical and Electronic Engineering, University Tun Hussein Onn Malaysia \\ ${ }^{2}$ Faculty of Civil and Environmental Engineering, University Tun Hussein Onn Malaysia \\ asitizuraidahzainudin@gmail.com, baziman@uthm.edu.my, cariff@uthm.edu.my, \\ faiz@uthm.edu.my
}

\section{Keywords: seismic surface wave, non destructive testing, surface wave}

\begin{abstract}
This research explores the use of the seismic surface wave technique which is called as a spectral analysis of surface wave (SASW) for investigating the shallow soil profile. The testing was conducted on soft ground located at Universiti Tun Hussein Onn Malaysia (UTHM). The testing was conducted using a new developed in-house seismic surface wave testing system. An impact source using $5 \mathrm{~kg}$ hammer is used to generate seismic energy and four differencesarrangement of the source to receiver distances to produce soil profile. The profile of phase velocity was obtained at a depth of $0.15 \mathrm{~m}$ to $1.8 \mathrm{~m}$ were between $68 \mathrm{~m} / \mathrm{s}$ and $95 \mathrm{~m} / \mathrm{s}$. The results were calibrated with the hand vane shear test which is used to obtain the undrained shear strength and thus converted empirically to seismic velocity at $45 \mathrm{~m} / \mathrm{s}$ and $95 \mathrm{~m} / \mathrm{s}$. The result shows good agreement between velocity obtained from the surface wave testing system and hand vane shear test. Therefore, the seismic surface wave system has been proven can be used to determine the seismic velocity at shallow depth.
\end{abstract}

\section{Introduction}

The seismic based method is an advantage in the Geotechnical field due to the seismic velocity can be empirically derived to elastic parameters such as young modulus, bulk modulus and shear modulus [1]. The advantages for using seismic surface wave technique are cost effective because this technique offers a non- intrusive and non-destructive method. There are two types of seismic waves; which are body waves and surface waves. The body wave identifies the soil profile via reflected and refracted wave when the soil changes its stiffness. Meanwhile the surface waves utilized wave frequencies in order to identify the soil profile. When the material has different stiffness in depth, the surface wave velocity varies with frequency or wavelength, thus the surface wave velocity dispersed with depth. The characteristic surface wave velocities are a function of a frequency or wavelength [2]. This dispersive characteristic will help to perform a soil profiling. This study investigated the new developed in-house seismic surface wave testing system and tested on soft ground at Universiti Tun Hussein Onn Malaysia (UTHM).

\section{Methodology}

This field testing was conducted at the Research Center of Soft Soil at Universiti Tun Hussein Onn Malaysia (UTHM). The spectral analysis of surface wave (SASW) method uses the vibration signals from the transient seismic source and the signal was received by the sensors are recorded digitally by a data acquisition. The receivers will convert the vibration signal received in the voltage formed and thus sending the information to the data acquisition in order to convert the analog to digital formed. Then, the information can be analyzed on a personal computer using Matlab software. The signals in the time domain are then converted into the frequency domain using a Fast Fourier Transform (FFT), and thus determine the phase shifts of different frequencies at each receiver. The seismic data are analyzed to obtain the phase velocity of the wave that propagated through the soil at each reliable frequency or wavelength. The depth of soil information is revealed by simple estimation of the half of the wavelength [3]. 
The experiment was adopted two sensor type of Integrated Circuit Piezoelectric (ICP) accelerometer, which were oriented linear on the ground surface. The sensor is used to detect the wave generated from an impulsive source of $5 \mathrm{~kg}$ hammer. The energy of surface wave propagates mechanically along the surface of a medium and their amplitude decreases with increasing distance [4]. Figure 1 shows the experimental layout for SASW system in this research. The arrangements of the source and receiver distance at $0.5 \mathrm{~m}, 0.10 \mathrm{~m}, 0.15 \mathrm{~m}$ and $0.2 \mathrm{~m}$. Based on Figure 1 shows the testing setup where $\mathrm{d}$ is the distance from the seismic source to first receiver and $\Delta \mathrm{xis}$ the distance between two receivers. It was recommended to arrange in equal distance between $\mathrm{d}$ and $\Delta \mathrm{x}$ [5].

The hand vane shear test was also conducted at the same location where the seismic surface wave testing conducted. The vane was pushed to the ground at intervals of $150 \mathrm{~mm}$ depth to obtain the undrained shear strength at each depth of 2 meters.

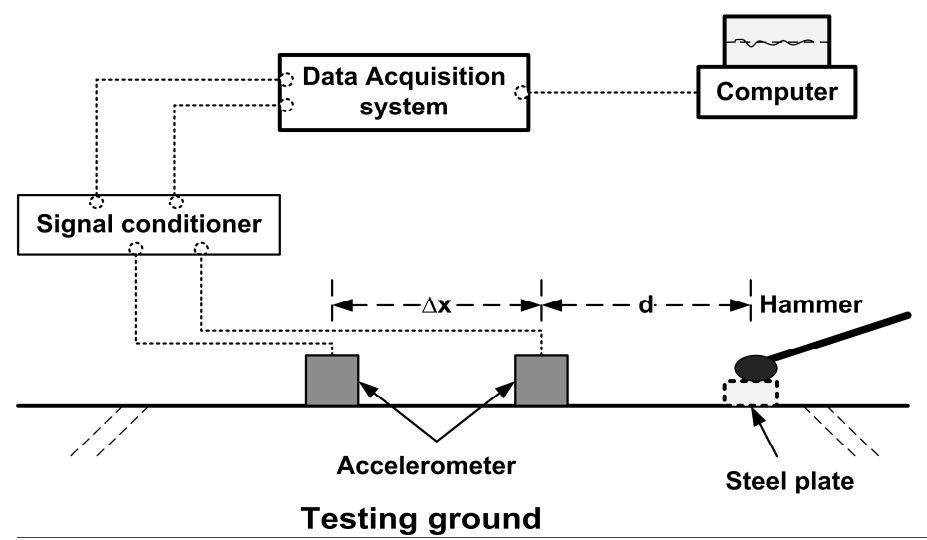

Fig.1: The seismic surface wave experiment setup.

\section{Result and Discussion}

Written Matlab software is used to analyze the captured seismic wave data using a compatible personal computer. The computer was connected to a National Instruments data acquisition system. The recorded signals from data acquisition system were transformed to the frequency domain by using a Fast Fourier Transform (FFT) process in order to obtain its magnitude and phase component of each frequency. The frequency had above $20 \%$ of the amplitude was accepted and then calculated its surface wave velocity at a given frequency by the equation (1) and (2) [6].

$t(f)=\Phi(f) /(360 f)$

$\mathrm{V}_{\mathrm{r}}=\mathrm{d} /(\mathrm{t}(\mathrm{f}))$

Where $t(f)$ is the travel time, $\Phi(f)$ is the phase difference, $d$ is the source to receiver distances in meter and $V_{r}$ the surface wave velocity at a given frequency. Figure 2 shows the graph of phase velocity versus wavelength via a combination of four arrangement distances between source and receiver spacing; $0.5 \mathrm{~m}, 1 \mathrm{~m}, 1.5 \mathrm{~m}$ and $2 \mathrm{~m}$. The wavelengths between $0.3 \mathrm{~m}$ and $3.6 \mathrm{~m}$ were represented 0.15 to 1.8 meters depth of soft soil information via simple depth estimation analysis. The averaged phase velocity for the receiver spacing of $0.5 \mathrm{~m}$ to $1 \mathrm{~m}$ and 1.5 to $2 \mathrm{~m}$ were $68 \mathrm{~m} / \mathrm{s}$ and $95 \mathrm{~m} / \mathrm{s}$ respectively. 


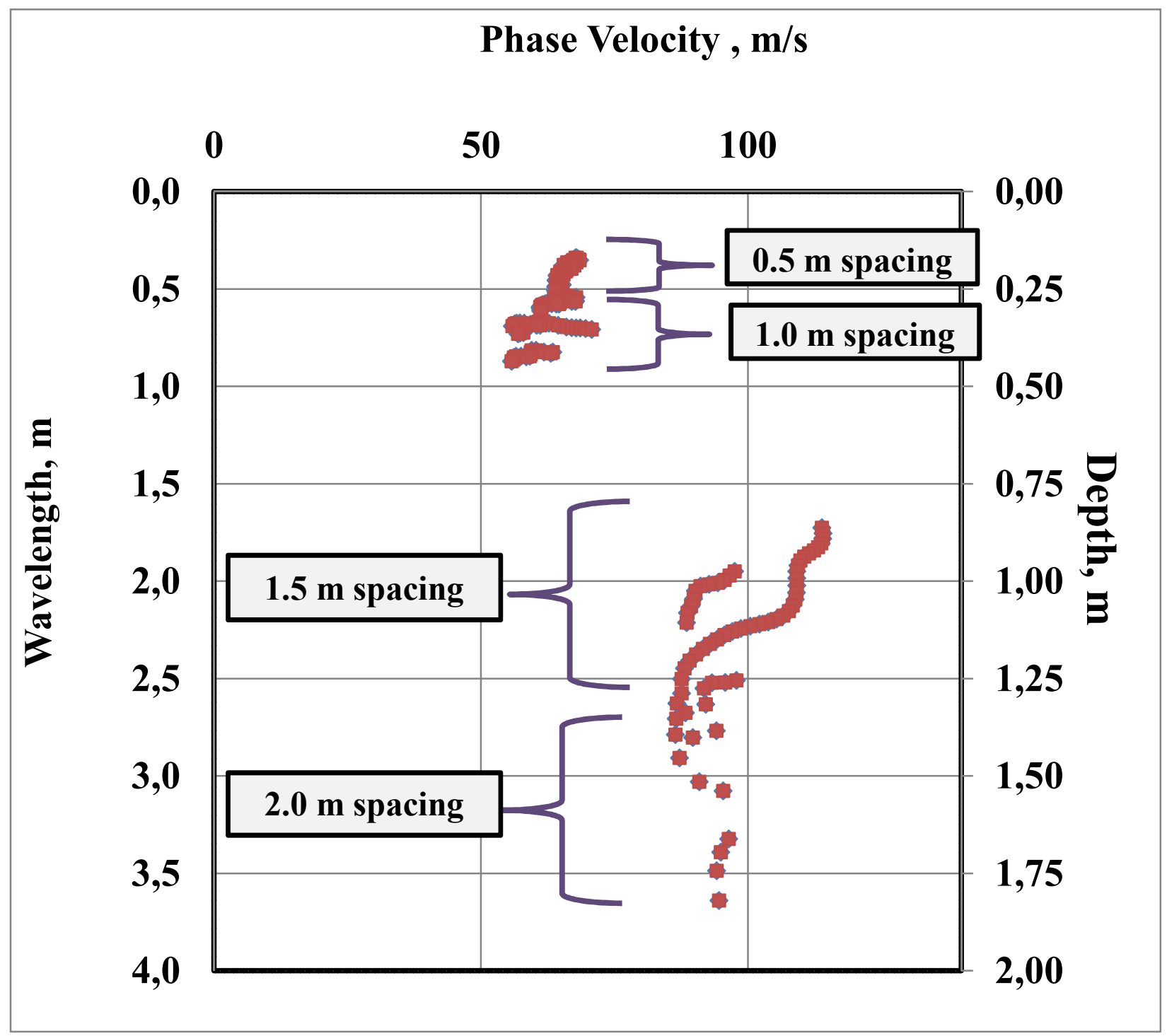

Fig. 2: The phase velocity versus wavelength via combination of 4 array spacings.

The hand vane shear test was conducted at the same location spectral analysis of surface wave (SASW) testing. The results showed the undrained shear strength was in the range of $16 \mathrm{kPa}$ to 33 $\mathrm{kPa}$. Hand vane shear testing was used to provide a comparison with the result obtained by the SASW system. The undrained shear strength parameter can be correlated empirically to the surface wave velocity $\left(\mathrm{V}_{\mathrm{r}}\right)$, and then the shear wave velocity $\left(\mathrm{V}_{\mathrm{s}}\right)$ via the empirical conversion, as established by Mattsson et al. [7] using equation 3 and 4.

$\mathrm{c}_{\mathrm{u}}=0.0424 \mathrm{~V}_{\mathrm{s}}^{1.462}$

$\mathrm{V}_{\mathrm{r}}=0.955 \mathrm{~V}_{\mathrm{s}}$

Where $V_{s}$ is the shear wave velocity, $V_{r}$ is the surface wave velocity and $c_{u}$ is the undrained shear strength. The undrained shear strength $\left(c_{u}\right)$ was converted to the surface wave velocity at 45 $\mathrm{m} / \mathrm{s}$ and $95 \mathrm{~m} / \mathrm{s}$. Meanwhile, the measured of the surface wave phase velocity of the spectral analysis of surface wave (SASW) system in this research area in averaged about $68 \mathrm{~m} / \mathrm{s}$ and $95 \mathrm{~m} / \mathrm{s}$ at $0.5 \mathrm{~m}$ and $1.5 \mathrm{~m}$ depth, respectively. These converted phase velocities were in good agreement with the measured phase velocities obtained using SASW testing

The capability to evaluate the velocity of soil with depth is important in Geotechnical investigation as well as in the quality testing. The depth of investigating profile is related to the 
wavelength. The location of the seismic surface wave velocity is represented by the volume of measurement, which is in a function of the vertical and the horizontal span of the soil properties. The sampling volume is based on the elliptical particle movement, which in turn is a function of its wavelength. The shape and size of the affected region of measurement in the medium in both lateral and vertical dimensions could be used to understand the variation of the phase velocity. The testing was conducted at the site where the soil properties are slightly changed horizontally and vertically, and thus the phase velocity from seismic testing was slightly deviated. The result shows the phase velocity was between $68 \mathrm{~m} / \mathrm{s}$ and $95 \mathrm{~m} / \mathrm{s}$.

\section{Conclusion}

The sensor spacing influences the depth the spectral analysis of surface wave (SASW) testing. The receiver spacings controlled the sampling volume, thus if the soil properties horizontally and vertically changed will affect the phase velocity. The seismic surface wave testing system used in this research was built in-house demonstrated a strong correspondence with the hand vane shear test. Furthermore, these did concur very well with previous pertinent literature.

\section{Acknowledgements}

The authors would like to thank the University of Tun Hussein Onn, Malaysia, and the Ministry of Education, Malaysia, for their generous granted of this research, FRGS vot. 1061.

\section{References}

[1] Clayton, C.R.I.. Stiffness at small strain: research and practice. Géotechnique, 61 (2011) (1): 537.

[2] Socco, L.V. and Strobbia, C. Surface wave method for near-surface characterization: a tutorial. Near Surface Geophysics, (2004). 165-185.

[3] Matthews, M.C., Hope, Y.S. and Clayton, C.R.I. The use of surface waves in the determination of ground stiffness profiles. Proceedings of the Institution of Civil Engineers Geotechnical Engineering. 119 (1996): 84-95.

[4] Al-Hunaidi M.O. Insight on the SASW non-destructive testing method. Canadian Geotechnical Journal, 20 (1993): 940-950

[5] Abbiss, C.P. Shear wave measurements of the elasticity of the ground. Géotechnique, 31(1) (1981): 91-104.

[6] Ganji, V., Gucunski, N., and Maher, A. Detection of underground obstacles by sasw methodnumerical aspects. Journal of Geotechnical and Geoenvironmental Engineering, ASCE, 123(3) (1997): 212-219

[7] Mattsson, H., Larsson, R., Holm, G., Dannewitz, N. and Eriksson, H. "Down-hole technique improves quality control on dry mix columns." In Proceedings of the International Conference on Deep Mixing Best Practice and Recent Advances, Stockholm, Sweden, Vol. 1, (2005) pp. 581-592.

[8] Madun, A., Jefferson, I., Foo K.Y., Chapman, D.N., Culshaw, M.G. and Atkins, P.R. Characterization and quality control of stone columns using surface waves testing. Canadian Geotechnical Journal, Vol. 49, No. 12, (2012) pp. 1357-1368 